\title{
A EDUCAÇÃO POPULAR AFIRMANDO VALORES COMUNAIS ATRAVÉS DA PEDAGOGIA DE ALICERCE: A REDE DE ARTE-EDUCAÇÃO SER-TÃO BRASIL
}

\author{
EDUCACIÓN POPULAR QUE AFIRMA LOS VALORES COMUNALES A \\ TRAVÉS DE LA PEDAGOGÍA DE ALICERCE: LA RED DE ARTE - EDUCACIÓN \\ SER-TÃO BRASIL
}
POPULAR EDUCATION AFFIRMING COMMUNAL VALUES THROUGH PEDAGOGY OF ALICERCE: THE ART-EDUCATION NETWORK SER-TÃO BRAZIL

Sergio Ricardo Santos da Silva ${ }^{1}$

\section{RESUMO}

Este trabalho levanta questões acerca do desafio de entender o contexto educacional estruturante e estruturado, de como afeta a educação formal ou não-formal e como movimentos sociais e educadores populares propõem uma educação outra. O maior desafio foi e é compreender como educadores, jovens, crianças, adultos e idosos conseguem afirmar nas suas elaborações de vida nas interações didáticas, aspectos do seu viver cotidiano em movimento articulado em rede de Arteeducação. Analisa a importância da relação da cultura popular e a educação como canal importante nas elaborações do conhecimento voltado para a valorização dos saberes que estruturam o pensamento comunal. Optamos por desenvolver uma abordagem qualitativa percorrendo um olhar investigativo envolto das contribuições da Rede de Arte-educação SER-TÃO Brasil, organizada na Bahia, com suas produções de saberes da cultura popular.

Palavras-chave: Cultura popular. Educação Popular. Arte-educação. Pensamento Comunal. Movimento Social

\begin{abstract}
This paper raises questions about the challenge of understanding the structuring and structured educational context, how it affects formal or non-formal education, and how social movements and popular educators propose another education. The biggest challenge was and is to understand how educators, young people, children, adults and the elderly can affirm in their elaborations of life in didactic interactions, aspects of their daily living in an articulated movement in an Art Education network. It analyzes the importance of the relationship between popular culture and education as an important channel in the elaboration of knowledge aimed at valuing the knowledge that structures
\end{abstract}

\footnotetext{
${ }^{1}$ Doutorando e Mestre em Educação e Contemporaneidade - Universidade do Estado da Bahia UNEB. Pedagogo. Professor de Ensino Fundamental na Prefeitura Municipal de Salvador/BA Brasil. Grupo de Pesquisa Teoria Social e Projeto Político Pedagógico (TSPPP). E-mail: sergiobahialista2@gmail.com
} 
communal thinking. We chose to develop a qualitative approach through an investigative look wrapped around the contributions of the SER-TÃO Brazil Art Education Network, organized in Bahia, with its productions of knowledge of popular culture.

Keywords: Popular culture. Popular education. Art education. Communal thinking. Social movement

\section{RESUMEN}

Este artículo plantea preguntas sobre el desafío de comprender la estructuración y el contexto educativo estructurado, cómo afecta la educación formal o no formal, y cómo los movimientos sociales y los educadores populares proponen otra educación. El mayor desafío fue y es comprender cómo los educadores, jóvenes, niños, adultos y ancianos pueden afirmar en sus elaboraciones de la vida en interacciones didácticas, aspectos de su vida diaria en un movimiento articulado en una red de Educación Artística. Analiza la importancia de la relación entre la cultura popular y la educación como un canal importante en la elaboración del conocimiento destinado a valorar el conocimiento que estructura el pensamiento comunitario. Elegimos desarrollar un enfoque cualitativo a través de una mirada investigativa en torno a las contribuciones de la Red de Educación Artística SER-TÃO Brasil, organizada en Bahía, con sus producciones de conocimiento de la cultura popular.

Palabras clave: cultura popular. Educación popular. Educación artística. Pensamiento comunitario Movimiento social

\section{INTRODUÇÃO}

O processo de estudo a respeito da educação popular que afirma (re) elaborações de valores comunais de culturas sertânicas do semiárido baiano desencadeou-se a partir de uma perspectiva de pesquisa qualitativa de cunho etnográfico junto a jovens e adultos de comunidades de Salvador e cidades do interior da Bahia que criaram a Rede de ArteEducação SER-TÃO Brasil, a qual será abordada com mais detalhes ao decorrer deste texto, que é um desdobramento do estudo do Mestrado em Educação e Contemporaneidade e das vivências junto ao movimento.

Assim, trazemos neste texto reflexões e provocações a respeito do que representa o princípio inaugural das suas territorialidades por meio da articulação em rede pelos grupos culturais dessas comunidades e cidades que compõem este movimento social e levanta outras formas lúdico-estéticas de anunciação e questionamentos.

Assim, neste trabalho tivemos como objetivo compreender como coletivos culturais que compõem a Rede de Arte-educação SER-TÃO Brasil conseguem afirmar nas suas produções arte-educativas aspectos do seu viver cotidiano, legado dos patrimônios 
civilizatórios aos quais pertencem. Buscar alcançar esse objetivo implicou em analisar os processos de organização deste movimento social em rede.

Tivemos como palco de vivências arte-educativas, nas quais os envolvidos neste movimento social construíram planos de atuação e monitoramento de políticas publicas a partir de seus coletivos culturais e suas expressões de arte popular, os encontros anuais do Festival de Arte-educação SER-TÃO Brasil.

O trabalho é alicerçado na pesquisa qualitativa, buscando um enfoque que “corresponde a concepções ontológicas e gnosiológicas específicas, de compreender e analisar a realidade" (TRIVINÕS, 1987, p. 117). Assim, corroboramos com Trivinõs quando o mesmo traz como um dos enfoques na pesquisa qualitativa: o enfoque subjetivistacompreensivista.

A escolha por esta abordagem que privilegia a subjetividade dos envolvidos na pesquisa, no nosso processo investigativo, busca compreender como os sujeitos deste movimento conseguem afirmar nas suas composições arte-educativas em rede, aspectos do seu viver cotidiano, legado dos patrimônios civilizatórios aos quais pertence.

\section{INICIANDO O ENTRELAÇAR DA ÉTICA DA COEXISTÊNCIA}

Exercer o direito de afirmar as diversas formas de estar no mundo é, sem dúvida, imprimir nossa marca na história, formando assim uma pluralidade que coexiste, afirmando a identidade cultural que nos sustenta - ressaltando que, afirmar passa longe da concepção de impor.

Vivemos um período de incertezas e de muitas certezas também. Uma certeza é a de que é preciso que o mundo "vá no oitão das tapera / Onde a dô e o luto mora / Abra o currá da mizéra / E bote a fome pra fora.” (ZÉ DA LUZ, 1949, p. 163)

Dentro das elaborações eurocêntricas de mundo, a construção de um diálogo a partir dos entre-lugares e dos inter-textos (SERPA, 2004) que realcem os laços comunais através da linguagem que anuncia nosso ser diante do mundo, indo contra a "maré do recalque", fazse necessário. É preparar uma nova forma de anunciar novas configurações de mundo, o simbólico característico de outras formas de existência e contemplação. Um simbólico que é negado por outras elaborações centradas no conhecimento e palavra normatizados.

Quando falamos em realçar os laços comunais, nos referimos à consciência de coexistência, de uma referência a princípios inaugurais que interagem com elementos Revista Educação e Ciências Sociais (ISSN: 2595-9980), Salvador, v.2, n.3, 2019 
existenciais que vão surgindo durante o caminhar de diversas populações, tecendo assim a "teia das relações de coexistência" (ARAUJO, 2007, p. 86) que tem um cordão umbilical ligado a uma origem comum, a referenciais míticos e ancestrais que tratam do "sentido imanente dado a símbolos ativos na história sócio-comunitária" (SODRÉ, 1999, p. 177), como memórias ainda presentes nas narrativas míticas e no cotidiano das comunidades.

Dinâmicas como as africano-brasileiras e sertanejas, de configuração de mundos que coexistem numa dinâmica atemporal, mostram o quanto a dinâmica de compartilhar saberes a partir do preparo ancestral tem profundo significado e contextualização de conhecimentos mais que pertinentes para a formação humana.

"Os repertórios da tradição que estão sedimentadas no éthos são constituídos de elementos vivos e dinâmicos, de tesouros simbólicos e mitopoéticos originários que configuram a existência e a coexistência de um povo. É um manancial de sabedorias tecida na trajetória das travessias dos indivíduos humanos pelos vãos e desvãos de suas vivências no mundo" (ARAUJO, 2007, p. 87).

Transpor este manancial de sabedorias tecidas é o que nos fala Miguel Almir Araujo, pois isso contempla dinâmicas arte-educativas, numa perspectiva pluricultural de valorização dos mestres da cultura popular e seu rico legado que contempla os aspectos existências, míticos, ancestrais dos povos que compõem o povo brasileiro.

Buscar entender este universo é condição mais que indispensável, pois "a dinâmica de expansão existencial das diversas contemporaneidades" (LUZ, 1999. p 01) configura força, pulsão de agregação, sensibilidade e respeito à alteridade, pois "de um lado a ciência / Que tem por sede a escola / Do outro a sapiência / Que o povo tem na caixola" (VIEIRA, 2005, p. 01).

Os versos de Antonio Vieira que entrelaçam nossas reflexões até aqui, como uma agulha poética que alinhava os saberes e fazeres do nosso povo, fazem parte do seu livreto de cordel intitulado "A peleja da Ciência com a Sabedoria Popular" (2005). Um poço de sabedoria - tanto da "ciência acadêmica" quanto da ciência que emana dos legados ancestrais - se abre e transbordam dádivas, riquezas, contribuições que enaltecem e reafirmam o quanto temos esperteza misturada à sabedoria do povo, que podem contribuir significativamente para o processo educativo do ser humano, assim como, podem contribuir para que o educando revele sua forma de ver o mundo e possa se afirmar enquanto jovem integrante de redes de alianças, vínculos societais tão intrínsecos ao seu estar no mundo.

Revista Educação e Ciências Sociais (ISSN: 2595-9980), Salvador, v.2, n.3, 2019 
Maffesoli também contribui significativamente para esta reflexão e entrelaçamento:

Nesta perspectiva, o banal, isto é, o que escapa à imposição dos poderes, pode ser objeto de um real investimento. A situação vivida, por minúscula que seja, provoca um curto-circuito nas falsas oposições; ao contrário do que possa parecer, ela se faz espetáculo, verbaliza sua profunda ambivalência, é a um tempo isto e aquilo. E por este fato ela reconhece que por tal ambivalência a vida pode ser vivida, apesar de tudo. (MAFFESOLI, 2007, p. 230)

Quando Maffesoli (ibid) nos traz o quanto o "banal" pode ser objeto de um real investimento, encaramos como uma atitude política, uma forma de trazer à tona a importância da afirmação do estar aqui além do que é imposto. E por esta atitude subentende que o curto-circuito nas falsas oposições é este levante das diversas perspectivas de existências, (re)elaborações de valores no âmbito do processo educativo.

$\mathrm{Na}$ escola isso era pra ter nota

Professora fazia até um bolo

Um motivo de festa, um estouro

Pra saudar os meninos exemplares

Os nomes dos poetas Populares

Deveriam estar na boca do povo." (VIEIRA, 2005, p. 56).

Acreditando na perspectiva que tudo está entrelaçado no refletir ao fazer, no deleitarse ao criar "as aprendências que sedimentam os Sentidos do existir" (ARAUJO, 2008, p. 76), associamos aqui, o prazer ao contexto educacional, tão esquecido neste espaço de construção de conhecimento. A partir da poesia, da percussão, da capoeira, das toadas de viola, do rap, revitalizam constantemente um "sistema cuja complexa trama simbólica, revitaliza e reforça a existência no aqui e agora". (LUZ, 1999, p. 51). Assim, ressaltamos que todo este universo real/simbólico que se reverbera no povo e pelo povo, também "se aprochega" nos espaços educativos, institucionalizados ou não, formais ou não, configurando-se uma educação outra. Talvez até a terceira margem do rio.

Nossos educandos, a partir de dinâmicas educativas alicerçadas na cultura popular, recriam novas formas de anunciar e afirmar seu continuum civilizatório, expressando através da oralidade e do seu registro, o contexto político e a riqueza do imaginário/simbólico. Assim, busca-se (re)estruturar, serrar as "grades curriculares" impostas pelo Aparelho Ideológico chamado Escola, que faz com que "a parte substitua o todo, reprimindo-o,

Revista Educação e Ciências Sociais (ISSN: 2595-9980), Salvador, v.2, n.3, 2019 
recalcando-o, e deformando-o. Nesse sentido, a totalidade da instituição escolar se caracteriza por práticas cotidianas constantes de afirmação e reafirmação da simulação da sociedade" (LUZ, 1999, p. 61).

Esta atitude problematiza o colonialismo que ainda guia, rege, estrutura as dinâmicas existências e didático-pedagógicas nos espaços educativos, principalmente nos institucionais:

O colonialismo - ou, como alguns preferem, a "colonialidade"- é ainda hoje a persistência desse primado do Um absoluto sobre o pluralismo cultural, em especial nas ideologias que confluem para as instâncias educacionais por meio de textos canônicos e por informação pública. (SODRÉ, 2012, p. 22).

Entender e (re)colocar a educação popular, tendo-a como elo entre o saber informacional e o saber vivencial é, para nós, suprimir este "Um" absoluto que está sobre o pluralismo cultural, que Muniz Sodré nos fala.

Assim, pretendemos aqui desencadear uma reflexão acerca de valores e princípios que preparem outra forma de anunciar as configurações de mundo dos educandos e expandir seu legado cultural, irradiando saberes. Este objetivo foi perseguido durante o entrelaçamento de saberes de diversos autores estudados durante nossa caminhada como pesquisador junto às linguagens lúdico-estéticas da cultura popular que compõem o universo dos nossos educandos.

Muitas linguagens fizeram parte do nosso "pilar" na Educação, buscando pensar outras formas de configuração de mundo que apresentem novos horizontes, algumas incertezas e desafios para toda a humanidade. Contribuições essas que acreditamos ser de extrema importância para educadores do século XXI.

Diante destas questões e inquietações, se faz de extrema importância dialogarmos, sentirmos e expressarmos a grande contribuição de Edgar Morin, ao se debruçar acerca do futuro da humanidade no seu livro "Os setes saberes necessários à Educação do futuro" (MORIN, 2000). Para ele, esse futuro - para que realmente exista para as futuras gerações deve perpassar pela Educação. Assim, durante sua escrita, levanta questões relevantes, expõe problemas centrais ou fundamentais, que junto a outras questões, também se tornam ignoradas ou esquecidas, questões essas que precisam ser também problematizadas para se ensinar no próximo século. 
Assim, ensinar neste século é levar em consideração aspectos mais amplos que colocam em xeque esses processos que a modernidade instaurou nas nossas dinâmicas existenciais, que buscam recalcar a todo custo outras formas de ser e estar neste mundo fragmentado, até porque "o mundo está em descontrole" (NASCIMENTO, 2006, p. 49) como vimos acontecer com a comunalidade do Quilombo Rio dos Macacos $^{2}$ (Salvador/BA), durante uma ação da Marinha do Brasil para colocar em prática um pedido de "reintegração de posse" de um lugar ancestral, cheio de redes de alianças, em 2012.

E Antonio Dias Nascimento vai além, nas suas reflexões acerca desses acometimentos, quando afirma que:

A necessidade que temos de recorrer à memória do nosso processo civilizatório parece-nos de central importância para que possamos identificar alternativas eficazes para enfrentar a crise de valores humanos, éticos e identitários que nos acomete, seja como indivíduos, seja como nação (...). Por fim, a crise da cultura, que se caracteriza pela perda dos valores ligados à preservação da vida em todos os seus aspectos. (NASCIMENTO, 2006, p. 50)

Nascimento, nessa reflexão, problematiza as noções de modernidade, pósmodernidade e contemporaneidade, abordando o legado que a modernidade deixa para nós a partir da ciência objetiva e dos valores universais que desembocam na pós-modernidade.

Nossos educandos, a partir de dinâmicas educativas alicerçadas na cultura popular, recriam novas formas de anunciar e afirmar seu continuum civilizatório, expressando através da oralidade e do seu registro, o contexto político e a riqueza do imaginário/simbólico. Assim, busca-se (re)estruturar, serrar as "grades curriculares" impostas pelo Aparelho Ideológico chamado Escola, que faz com que "a parte substitua o todo, reprimindo-o, recalcando-o, e deformando-o. Nesse sentido, a totalidade da instituição escolar se caracteriza por práticas cotidianas constantes de afirmação e reafirmação da simulação da sociedade" (LUZ, 1999, p. 61).

\footnotetext{
${ }^{2}$ O quilombo Rio dos Macacos está localizado dentro da Vila Naval de Aratu, em Simões Filho, região metropolitana de Salvador, Bahia. (...) Inicialmente o local chamava-se Fazenda dos Macacos e pertencia à família Martins, que abdicou do terreno devido ao declínio da produção da cana de açúcar. Os remanescentes de quilombolas permaneceram no local vivendo tradicionalmente por aproximadamente 150 anos. No início da década de 1960, parte das terras foi tomada para a construção de uma barragem. Posteriormente, em 1972, a situação foi agravada pelo início das obras da vila naval, sendo 57 famílias expulsas e sua estrada tradicional destruída pela marinha. Durante um tempo, para sair e entrar de suas terras pela base da marinha, as famílias que restaram foram obrigadas a usar um crachá humilhante, que os qualificava como invasores. Informações extraídas do site "A nova democracia". https://anovademocracia.com.br/no-127/5263-os-valentes-quilombolasde-rio-dos-macacos. Acesso em 05/01/2020.
} 
Ensinar a compreensão para uma ética da coexistência, para que não criem tantos que compõem o universo escolar, achando que cumprem o seu dever quando unificam os seres, fazendo com que através do recalque, neguem quem são e não se entendam como parte integrante de toda natureza e cultura que o cerca.

O dedicar-se só a dominar perde espaço e a pulsão para a compreensão, observar, vem à tona, pois "estamos em vias de reavaliar a complexidade do mundo e redescobrir a importância do jogo da diferença", fazendo assim com que destaquemos "as múltiplas criações ou situações de vida cotidiana, sem que, no entanto, as encerremos nos estreitos limites do finalismo". (MAFFESOLI, 2007, p. 125).

Acreditamos que o destino rumo ao restabelecimento da ética da coexistência, também perpassa pela consciência coletiva erguida e desenvolvida no caminho do eu em direção ao outro, no caminho do respeito à existência humana, com suas singularidades e pluralidades coexistindo no aqui e agora.

Compreender, nos dias atuais, como diz o dito popular, "vale ouro", pois cada vez mais as dinâmicas existências dos diversos povos mostram que devemos encarar a vida não para ser olhada, mas para ser conhecida. Para a concepção de uma pedagogia diferente é preciso respeitar as plurais formas de ser e estar no mundo: seus referenciais, sua forma de educar e de ver-se no mundo.

A partir dessa Pedagogia contextualizada com as redes de alianças locais que permeiam a instituição escolar, as múltiplas subjetividades humanas são (re)significadas na prática, aonde o diálogo proporciona um encontro dos múltiplos contextos e linguagens, afirmando que se ver no outro é fundamental para recriar a sua existência.

O processo de legitimação da estrutura, que compõem as instituições escolares hoje, as quais não dão espaço para essa pulsão dos valores comunais, abusam do seu "poder simbólico", que tem o "poder de construção da realidade que tende a estabelecer uma ordem gnoseológica: o sentido imediato do mundo" (BOURDIEU, 1989, p. 09). Assim, "legitima" os seus sistemas simbólicos que "exercem um poder estruturante porque são estruturados". (Ibidem).

\section{UM EXEMPLO DE EDUCAÇÃO POPULAR E PEDAGOGIA DE ALICERCE: A EXPERIÊNCIA DA REDE DE ARTE-EDUCAÇÃO SER-TÃO BRASIL}


O CRIA - Centro de Referência Integral de Adolescentes - é uma ONG que tem como missão provocar nas pessoas, por meio da arte-educação e do despertar de sensibilidades, atitudes transformadoras de si mesmas e da sociedade em que vivem, de forma coletiva e comunitária. Busca fortalecer o Sistema de Garantia dos Direitos da Criança e do Adolescente através da arte, estimulando assim a mobilização nas suas comunidades em busca de seus direitos.

Foi no CRIA que veio à tona o entendimento do quanto o plural brilhar do SER-TÃO brasileiro é rico e fundamental para a pulsão de vida dos diversos povos que compõem a identidade brasileira. E assim, durante os anos 2000, foi criada e articulada a rede SER-TÃO Brasil, composta pelo CRIA, por12 grupos comunitários organizados de Salvador e mais 16 cidades do interior da Bahia. Estes buscam, a partir de articulações político-culturais, pelo bem comum e possibilidade da vida simples e digna em cada lugar, inspirar novas experiências organizadas coletivamente, com e pela juventude, que valorizem a criatividade, a liberdade, a criação artística, as culturas tradicionais locais, a relação do homem com a terra e as formas solidárias de sobrevivência ${ }^{3}$. Esse espaço nos ensinou muito mais do que qualquer escola que passamos.

Na rede SER-TÃO Brasil, as dinâmicas existências de saberes e fazeres do povo realçam as cores, sentidos e cheiros que brotam da arte que vem da "ciência primeira" (LEVI-STRAUSS, 1989). É através dessa rede de articulação arte-educativa, fincada nas expressões populares, que são recalcadas, em diversos espaços, que muitas cidades, pessoas, grupos culturais criam, recriam e monitoram políticas públicas de cultura que realmente atendam aos anseios essenciais dos que realmente pulsam e vivem seu legado ancestral artístico, cultural e de formação.

O educar ganhou novas formas, no nosso coração e na nossa forma de conceber processos pedagógicos, graças aos aprendizados e vivências nessa Rede, com essas pessoas que acreditam no potencial do ser humano e na pulsão comunal que irradia ensinamentos de mestres da nossa cultura popular, como Seu Gervácio, Dona Aninha, Seu Roque, o sambador Roque Trabuco, que seguiam pendurando seus saberes e composições identitárias.

\footnotetext{
${ }^{3}$ Informações extraídas do Blog Rede Ser-tão Brasil. http://redesertaobrasil.wordpress.com/conheca-a-rede/ . Acesso em 07/01/2020.

Revista Educação e Ciências Sociais (ISSN: 2595-9980), Salvador, v.2, n.3, 2019
} 


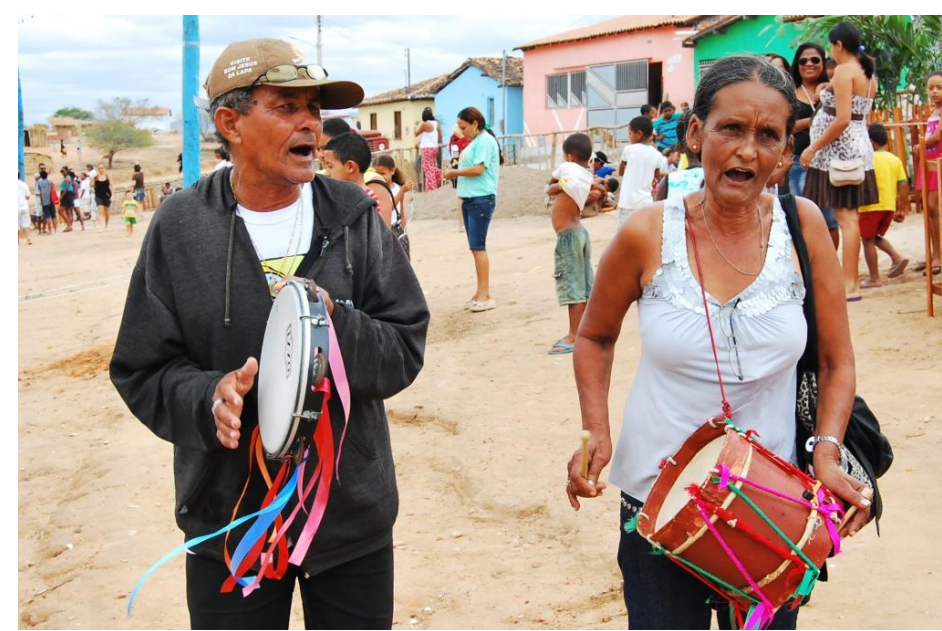

Figura 01 - Mestra Popular Dona Aninha, integrante da Rede Ser-tão Brasil ${ }^{4}$ Fonte: Acervo pessoal de Tássia Batista/ 2011

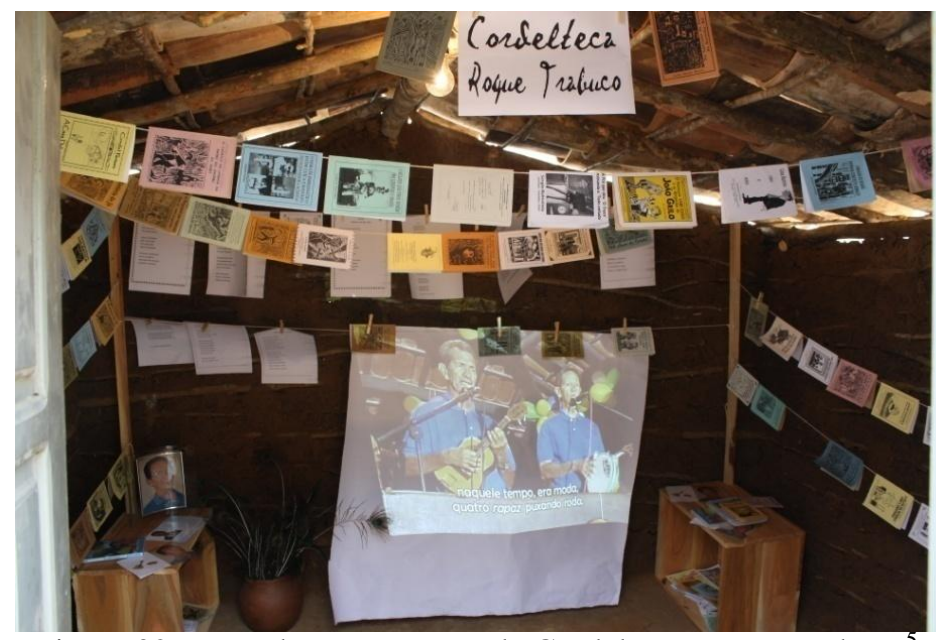

Figura 02-Festa da Inauguração da Cordelteca Roque Trabuco ${ }^{5}$ Fonte: Acervo pessoal de Tássia Batista, 2011.

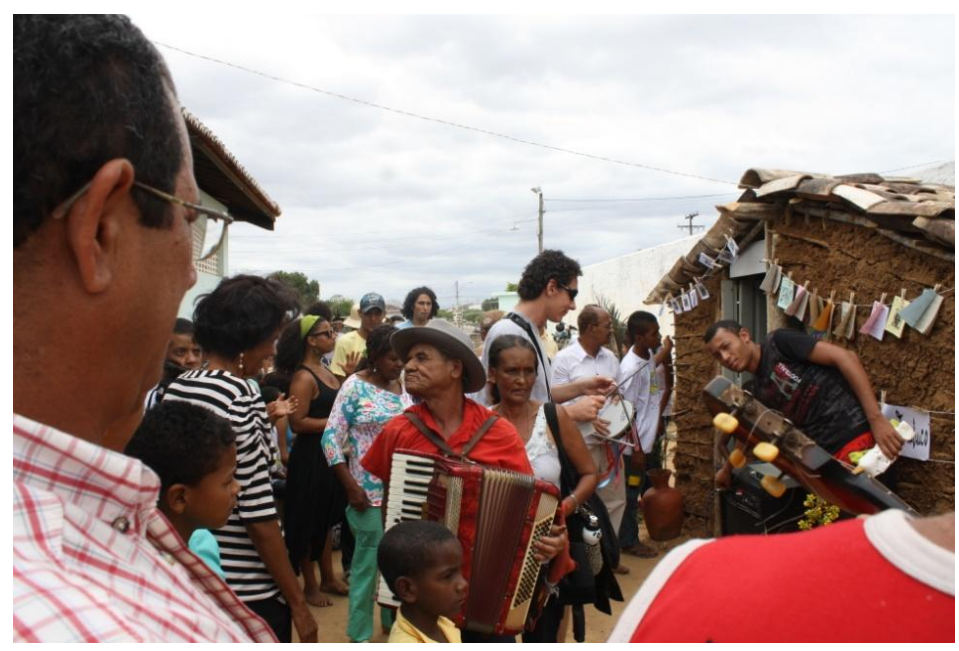

Figura 03 -Inauguração da Cordelteca Roque Trabuco ${ }^{6}$

\footnotetext{
${ }^{4}$ Sambadora de samba do sertão, da cidade Lafaiete Coutinho. Encontro Ser-tão Brasil - Boa Vista do Tupim.

${ }^{5}$ Festa da Inauguração da Cordelteca Roque Trabuco, na Escola Municipal de Boa Vista do Tupim, no Encontro Ser-tão Brasil - Boa Vista do Tupim / 2011

${ }^{6}$ Idem.
}

Revista Educação e Ciências Sociais (ISSN: 2595-9980), Salvador, v.2, n.3, 2019 
Foi neste contexto de Educação para uma nova Tribo Humana - pois era assim que nomeávamos nossas formas de educar através da arte que agrega os diversos saberes e fazeres do nosso povo, buscando formar jovens dinamizadores culturais que construíam um novo rito de passagem - que surgiram diversos grupos comunitários no qual agregavam um trabalho arte-educativo em rede.

Segundo Farias (2006, p. 25):

\begin{abstract}
Nesses códigos simbólicos está cunhada uma grande parte dos códigos genéticos culturais - uma espécie de DNA da cultura - da sociedade humana, uma vez que somos tatuados culturalmente, e é a partir do movimento de reinvenção das tradições que o processo sóciocognitivo-cultural de perpetuação da nossa existência simbólica se mantém.
\end{abstract}

Acreditando no movimento de (re)invenção das tradições, levantado por Farias, é que acreditamos no poder da palavra poética como instrumento de (re)elaborações de valores comunais nos processos educativos.

Este movimento atua em diversas frentes de articulação e monitoramento de políticas publicas culturais voltadas para a promoção e afirmação da cultura popular na educação formal e não-formal de Salvador e de diversas cidades do interior da Bahia. Encontros entre as cidades acontecem durante o ano para intercâmbios e planejamentos de ações conjuntas, em rede, por esses propósitos. Uma vez por ano era realizado em uma das cidades da rede, o Festival SER-TÃO Brasil, o qual era a culminância de todas essas ações e o momento de reunir autoridades da área da educação e cultura, artistas populares locais e de outras regiões do Brasil, para encaminhar novos processos de implementação da arte-educação pela cultura popular e viver arte produzida em cada território envolvido nesta rede de mobilização.

\title{
3 CONSIDERAÇÕES FINAIS
}

Para (re)pensar o papel da Educação neste processo de afirmação, precisamos de educadores-pesquisadores que mergulhem fundo no encantamento da pluralidade cultural, elaborando epistemes africano-brasileiras, ameríndias, sertânicas e (re)elaborando legados europeus a partir das dinâmicas existenciais e educativas para tecer redes de saberes que se

Revista Educação e Ciências Sociais (ISSN: 2595-9980), Salvador, v.2, n.3, 2019 
entrelacem em si mesmas e em outras redes, outros trançados que compõem nossa pluralidade cultural. Isso é tarefa mais que importante para qualquer educador.

O Brasil, sendo uma nação pluricultural, já é mais que constatado que sempre teve sua história contada longe da ótica popular.

Percebemos que a escola e professores, em uma escala considerável, são como "rês desgarrada / nessa multidão, boiada / caminhando a esmo"7, seguem sem a busca do despertar a curiosidade no educando, proferindo um educar que não contempla as plurais formas de existências que circulam o meio escolar, deixando de lado a riqueza das diversas estéticas da arte, tão primordial para um educar.

Cantar, contar histórias, recitar, tocar, sambar, aconselhar, tudo isso é alicerce de saberes que sustentam o viver do ser humano, pois o que seria de nós sem inter-relações, sem o encontro com o outro, com as outras coisas, consigo mesmo? E isso foi constatado nas vivências e observações junto a Rede de Arte-educação SER-TÃO Brasil, abordada aqui.

Encaramos o educador - projetando, sonhando com que todo educador um dia tornese arte-educador - da contemporaneidade como um "(re)inventador da Educação", como o protagonista de ações articuladas em rede que fortaleça e promova a educação popular.

Ressaltamos o quanto as insurgências de pedagogias de cada comunalidade, una e plural, alicerçadas nos seus princípios inaugurais - as quais chamamos de Pedagogias de Alicerce - são fundamentais para inaugurar outras formas de educar e de se ver na sua história, cantar sua aldeia e disseminar aprendizados mútuos que são construídos a partir de saberes e fazeres do seu povo local, dialogando sempre com o global.

\section{REFERÊNCIAS}

ALMEIDA, Márcio Nery de. Viver a comunalidade na escola: Para além das habilidades e competências do Currículo Escolar. Dissertação de Mestrado apresentada ao Programa de Pós-Graduação em Educação e Contemporaneidade da Universidade do Estado da Bahia UNEB; Salvador, 2007.

ARAUJO, Miguel Almir Lima de. Os sentidos da sensibilidade: sua fruição no fenômeno do educar. Salvador: EDUFBA, 2008.

ARAUJO, Miguel Almir Lima de. A ação de educar como rito de iniciação à ética da coexistência. In Revista FACED, n. 11, p. 83-99. Editora UFBA, Salvador, 2007.

\footnotetext{
7 Trecho da música "Lamento Sertanejo", de Gilberto Gil e Dominguinhos.

Revista Educação e Ciências Sociais (ISSN: 2595-9980), Salvador, v.2, n.3, 2019
} 
ASSARÉ, Patativa do. In: Cante lá que eu canto cá. Petrópolis: Vozes, $2^{\text {a }}$ ed., 1978

ASSARÉ, Patativa. Nordestino sim, nordestinado não. In: Ispinho e Fulô, $3^{\text {a }}$ Ed. Fortaleza-CE, 2002.

FARIAS, Carlos Aldemir. Alfabetos da Alma: histórias da tradição na escola. Porto Alegre: Sulina, 2006.

FREIRE, Paulo. Pedagogia da Autonomia: Saberes necessários à prática educativa, São Paulo. Paz e Terra, 1996.

LUZ, Narcimária Correia do Patrocínio. Abebe: a criação de novos valores na Educação. Salvador: Edições Secneb, 2000 (Coleção ComunitatisMundi).

LUZ, Narcimária Correia do Patrocínio. O reencantamento do mundo: perspectivas de análise para a compreensão do nosso tempo. Salvador, UNEB, 2008.

LUZ, Zé da. Brasil Caboclo. Seção de Livros da Empresa Gráfica "O Cruzeiro" S. A. Rio de Janeiro, 1949.

MAFFESOLI, Michel. Elogio da Razão Sensível. Petrópolis: Vozes. 1998.

MAFFESOLI, Michel. No fundo das aparências. Petrópolis: Vozes, 2005.

MAFFESOLI, Michel. O Conhecimento Comum: introdução à Sociologia Compreensiva. Porto Alegre: Sulina. 2007.

MORIN, Edgar. Os sete saberes necessários à educação do futuro. Tradução de Catarina Eleonora F. da Silva e Jeanne Sawaya ; revisão técnica de Edgard de Assis Carvalho. - 2. ed. - São Paulo: Cortez; Brasília, DF: UNESCO, 2000.

NASCIMENTO, Antonio Dias. In JUNIOR, Arnaud Soares de Lima [et al]. Educação e Contemporaneidade: desafios para a pesquisa e a pós-graduação. Rio de Janeiro: Quarter, 2006.

ROSA, Flávia Taís Mucarzel. O BrasíCabôcode Zé da Luz: um passeio pela representação do sertão e de si. Dissertação de Mestrado apresentada ao Programa de Estudo de Linguagens da Universidade do Estado da Bahia; Salvador, 2008.

SERPA, Felippe. Rascunho Digital: Diálogos com Felippe Serpa. Salvador: Edufba, 2004.

SODRÉ, Muniz. A verdade seduzida: por um conceito de cultura no Brasil. Rio de Janeiro: DP\&A, 2005.

SODRÉ, Muniz. Reinventando a Educação: diversidade, descolonização e rede. Rio de Petrópolis/RJ: Vozes, 2012.

TRIVIÑOS, Augusto N. S. Pesquisa Qualitativa. In: Introdução à pesquisa em ciências sociais: a pesquisa qualitativa em educação. São Paulo: Atlas, 1987. p. 116-175. Revista Educação e Ciências Sociais (ISSN: 2595-9980), Salvador, v.2, n.3, 2019 